\title{
MORRER SEM COMER E BEBER: UM OLHAR SOBRE A CESSAÇÃO VOLUNTÁ- RIA DE ALIMENTAÇÃO E HIDRATAÇÃO NO FIM DE VIDA
}

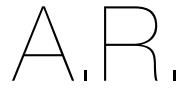
ARTIGO DE REVISÃO

1 Faculdade de Ciências da Saúde da Universidade Fernando Pessoa, Rua Carlos da Maia, n. ${ }^{\circ} 296$,

4200 - 150 Porto, Portugal

2 Hospital-Escola da Universidade Fernando Pessoa,

Avenida Fernando Pessoa n. ${ }^{150}$, 4420-096 Gondomar,

Portugal

${ }^{3}$ Unidade de Cuidados Continuados da Fundação Fernando Pessoa, Rede Nacional de Cuidados Continuados Integrados, Avenida Fernando Pessoa n. ${ }^{\circ} 150$,

4420-096 Gondomar,

Portugal

${ }^{4}$ Instituto de Bioética da Universidade Católica

Portuguesa,

Rua Diogo Botelho,

n. ${ }^{\circ} 1327$

4169-005 Porto, Portugal

`Endereço para correspondência:

Cíntia Pinho-Reis

Hospital-Escola da Universidad Fernando Pessoa, Avenida Fernando Pessoa,

n. ${ }^{\circ} 150$

4420-096 Gondomar, Portugal cintia.vp.reis@gmail.com

Histórico do artigo:

Recebido a 27 de outubro de 2020 Aceite a 30 de abril de 2021

\section{DYING WITHOUT EATING AND DRINKING: AN OVERVIEW ABOUT VOLUNTARILY STOPPING OF EATING AND DRINKING IN THE END OF LIFE}

Mariana Leitão de Oliveira'; Cíntia Pinho-Reis ${ }^{2-4}$

RESUMO

A presente revisão pretende compreender o estado da arte relativamente à cessação voluntária de alimentação e hidratação no que se refere a: definições, motivações, processo de morte, bem como a sua relação com os conceitos de suicídio assistido, eutanásia, autonomia e cuidados paliativos.

\section{PALAVRAS-CHAVE}

Cessação voluntária de alimentação e hidratação, Cuidados paliativos, Eutanásia, Fim de vida, Questões éticas, Suicídio assistido

ABSTRACT

The current review pretends to understand the state of the art regarding voluntarily stopping of eating and drinking in the end of life related to: definitions, motivations, process of death, and its relation to the concepts of assisted suicide, euthanasia, autonomy and palliative care.

KEYWORDS

Voluntarily stopping of eating and drinking, Palliative care, Euthanasia, End of life, Ethical issues, Assisted suicide

\section{INTRODUÇÃO}

Os avanços da medicina, sobretudo no século XX, foram inúmeros e continuam a sê-lo no tempo atual. O desenvolvimento científico, tecnológico, social e económico que tem vindo a ocorrer resolve muitos dos problemas de saúde. No entanto, no início do século XXI as populações são confrontadas com novos desafios que advêm da redução da mortalidade infantil e do aumento da esperança de vida, o que impulsiona um número cada vez maior de pessoas a atingir idades mais avançadas, colocando nos profissionais de saúde a necessidade de resolver cada vez mais problemas de doença avançada a progressiva, muitas vezes, terminal $(1,2)$. A impossibilidade de cura e o desenvolvimento tecnológico e científico permitiram manter a vida, prolongando o processo de morte, muitas vezes, de forma artificial, o que leva a processos de morte mais longos e complexos mas não necessariamente com maior qualidade de vida. Assim, prolongar a vida poderá resultar num fim de vida com dor total e sofrimento insuportáveis (2). Para alguns doentes, a morte já é calculável e esperada. No entanto, não é a morte em si que lhes origina medo, mas sim que a duração do processo de morte esteja associada à dor, à institucionalização, ao aumento dos cuidados prestados, à perda de autonomia, ao aumento da sobrecarga dos familiares e/ou cuidadores $(2,3)$.

A possibilidade de alcançar a terminalidade com sofrimento intolerável, tem vindo a incentivar muitos doentes a envolverem-se mais no processo de tomada de decisão em fim de vida, mais concretamente no que diz respeito à alimentação, nutrição e hidratação que desejam receber nessa fase como forma de controlar as circunstâncias da sua morte $(2,4)$. Assim, para alguns doentes competentes, a possibilidade de conseguirem um fim de vida com características definidas por si próprios, faz com que estes optem pela Cessação Voluntária de Alimentação e Hidratação (CVAH) (3).

A CVAH consiste em morrer sem comer e beber, sendo que, neste âmbito a pessoa doente encontra-se competente para efetuar esta decisão. Assim, a finalidade específica da CVAH consiste em antecipar a morte por interrupção de alimentação e hidratação por via oral, devido ao sofrimento insuportável e persistente originado pela doença $(2,3,5-10)$. De facto, a CVAH é uma forma de acelerar a morte praticada desde os tempos antigos (8) existente há milhares de anos, nomeadamente no Jainismo, uma das mais antigas religiões da Índia (3). Santhara, é a prática religiosa de jejuar voluntariamente até à morte, no qual os jainistas interrompem a alimentação e hidratação, acreditando-se 
que a fome os conduz à libertação da alma $(2,11)$. No Hinduísmo o jejum é também reconhecido como uma prática que tem como consequência a morte (3).

Nas últimas décadas a CVAH têm vindo a ser mais discutida como uma possibilidade, entre outras, de preservar a autonomia, de manter o controlo sobre a morte e de antecipá-la sem infringir os princípios éticos de beneficência, não-maleficência, justiça e autonomia (5). Contudo, a CVAH tem sido frequentemente incompreendida por familiares e alguns profissionais de saúde, sendo que, os conflitos morais e éticos emergem na equipa inter e multidisciplinar muito em parte pelo significado que a alimentação, a nutrição e a hidratação poderá ter na vida das pessoas (5).

\section{METODOLOGIA}

Foi realizada uma revisão narrativa da literatura com pesquisa na b-on, com as palavras-chave "voluntary cessation eating and drinking" AND "end of life" AND "ethical issues" AND "autonomy". Incluíram-se todos os artigos no período compreendido entre 2000 e 2020 com resumo, referências e texto integral disponíveis. Obteve-se um total de 860 publicações que após leitura do título e do resumo resultaram num total de 33 artigos. A pesquisa inicial foi complementada com a busca manual de sete artigos considerados pertinentes, perfazendo um total de 40 artigos analisados. Para além disso, recorreu-se a outras referências bibliográficas importantes, tais como um livro e o Código Deontológico da Ordem dos Nutricionistas. Assim, a presente revisão narrativa da literatura teve por base a análise de um total de 42 publicações.

\section{Cessação Voluntária de Alimentação e Hidratação Definições e Terminologia}

$\mathrm{Na}$ literatura a CVAH tem sido referida com outras denominações, incluindo: recusa voluntária de alimentos e líquidos, desidratação terminal voluntária, morte voluntária por desidratação, desidratação terminal, interrupção de comer e beber, recusa do doente em hidratação e nutrição e comportamento autodestrutivo indireto (3, $5,9,12)$.

A CVAH é descrita como uma ação de uma pessoa competente e capacitada, que voluntária e deliberadamente escolhe parar de comer e beber com a intenção primária de acelerar a morte, porque persiste um sofrimento inaceitável $(5,13-15)$. Esta definição não inclui a interrupção da nutrição ou hidratação por outros motivos, tais como a perda de apetite ou incapacidade de comer ou beber devido à progressão da doença $(5,7,10,16-18)$. A literatura descreve que a CVAH é mais frequentemente associada a pessoas com doença terminal ou irreversível $(3,6,7,13,17)$, sendo que não se destina a pessoas dependentes de nutrição e hidratação artificiais (5, 9).

Para alguns doentes cuja patologia é grave, a CVAH é encarada como uma forma célere e pacífica de antecipar a sua morte sem que seja obrigatório o envolvimento de terceiros (18). Na CVAH, os profissionais de saúde não têm a obrigação de informar os doentes sobre este tema sendo, no entanto, recomendado que o façam caso a pessoa doente demonstre interesse nestas temáticas (19). É importante salientar que os doentes são fisicamente capazes da ingestão de alimentos e líquidos pela via oral, porém, conscientemente optam por não o fazer $(3,13,17)$.

\section{Motivações}

Alguns doentes são motivados por fatores físicos, tais como a debilidade, a fraqueza e a dor. Entretanto, na maioria dos casos, as razões para o pedido de antecipação da morte são: cansaço do processo de morte, desejo de manter a sua autonomia e controlar as circunstâncias da morte, sensação de que a qualidade de vida é reduzida e a sensação de que a vida não tem significado $(3,5$, 7-10, 13, 16-18, 20). Outras razões apontadas são: deterioração do estado de saúde e o não ter perspetiva ou motivo para continuar a viver, pois os cuidados paliativos prestados são insuficientes e não são capazes de oferecer a paliação desejada $(5,13,14,17)$. Para além disso, a literatura descreve que também poderá ocorrer o sentimento de fardo para com os familiares, desespero, depressão e o desejo de morrer no domicílio (3, 5, 7-10, 13, 17, 18, 20-23). As pessoas doentes geralmente experimentam uma combinação desses motivos (9). Nesse contexto, todos os doentes têm o direito de recusar alimentos, líquidos ou nutrição e hidratação, porque é uma decisão aceite clínica e legalmente no que diz respeito ao doente competente $(17,24)$

O desejo de antecipar a morte pode variar ao longo do tempo (20), pois este exprime uma resposta ao sofrimento e ao desespero duradouro dos doentes com doença incurável e progressiva (25). É, por isso, muito importante que as equipas interdisciplinares de saúde examinem continuamente estas questões e tentem compreender os motivos que levam uma pessoa doente a escolher antecipar a sua morte, tendo sempre em conta que viver uma vida mais longa nem sempre significa viver com melhor qualidade de vida (3). Assim, um acompanhamento personalizado, direcionado ao conforto e bem-estar do doente pode ajudar a paliar a dor total, o sofrimento e outros sintomas, promovendo a qualidade de vida e o conforto até à morte (18).

\section{Processo de Morte}

Inicialmente, os doentes poderão continuar ativos, mas ao longo do tempo o cansaço, a fraqueza e a sonolência acabam por tomar conta dos mesmos. Quando se inicia a CVAH é muito importante que os doentes sejam acompanhados, pois sintomas tais como tonturas e fraqueza podem ocorrer. A sensação de sonolência faz com que os doentes deixem de estar num estado mental ativo, levando alguns deles ao estado de inconsciência ou ao estado de coma (3). Após iniciar a CVAH, o doente permanece vivo por um período médio de até três semanas $(5-7,9,17,26,27)$, o que lhe permite neste intervalo de tempo, refletir e reconsiderar a sua decisão ou relembrar aos familiares da sua opção e preparar-se da melhor forma possível para dizer adeus $(5,26)$. A morte ocorre por desidratação devido à interrupção de alimentação e de hidratação e à perda de água através da transpiração e da micção (3).

Os sintomas nas primeiras 24 horas são boca e pele secas $(3,18$, 26 , 28). A sensação de fome e sede geralmente desaparecem após o primeiro ou segundo dia embora nem todos os doentes experienciem estas sensações $(9,13)$. A sensação de sede tem início no lento processo de desidratação que ocorre ao nível renal e cerebral. Recetores no cérebro detetam alteração na concentração dos solutos existentes no corpo, levando consequentemente à secreção da vasopressina, hormona antidiurética que é secretada em caso de desidratação (3, 9). Esta hormona faz com que os rins conservem a água no organismo até certo ponto, diminuindo o volume da urina. Assim, o cérebro informa o organismo da sensação de sede que, numa situação normal levaria a pessoa à sua reidratação $(3,13)$. Para que os doentes consigam aliviar a sensação de sede e de xerostomia, poderão ser dados pequenos goles de água bem como raspas de gelo ou saliva artificial. Assim, o volume de água no organismo não aumenta significativamente, pois os recetores existentes na boca informam o cérebro de que a sede foi saciada. Não havendo entrada de água no organismo, após 24 horas a concentração de urina diminui 
o que leva a que os rins absorvam água no sangue e reabsorvam hidrogénio através do organismo. Assim, o sangue torna-se ácido, informando o organismo que este se encontra desidratado. Devido ao excesso de acidez no sangue (acidose metabólica) os doentes nesta fase poderão começar a hiperventilar $(3,9)$.

Entre 24 a 48 horas após iniciar a CVAH, esgotam-se as reservas de hidratos de carbono e o organismo inicia a metabolização do tecido muscular, ocorrendo a libertação de cetonas. Estas consistem em compostos orgânicos produzidos pelo organismo quando o mesmo não é capaz de usar a glicose como fonte de energia utilizando a gordura. As cetonas são libertadas na corrente sanguínea e o organismo entra em cetonemia. Pelo efeito da libertação de endorfinas, os doentes poderão entrar num estado de euforia que pode durar vários dias $(3,13)$. Nesta fase, os doentes são ainda capazes de comunicar com as pessoas que os rodeiam. Com a desidratação, as células do cérebro perdem a sua função da troca de moléculas tornando-as menos ativas, podendo o doente atingir um estado de coma permanente. Devido à desidratação, o organismo perde a capacidade de originar impulsos elétricos, o coração deixa de bombear de forma normal, os batimentos cardíacos tornam-se irregulares, culminando em arritmia cardíaca. Esta ocorre quando o doente se encontra em coma, impedindo o mesmo de sentir qualquer tipo de dor $(3,9)$.

A literatura indica que a morte por CVAH é considerada suave, confortável, pacífica, sem sofrimento ou dor, tranquila, mantendo a dignidade do doente até ao fim e garantindo a proteção da autonomia e da integridade física da pessoa doente $(3,5,6,17,27,29)$.

A duração da CVAH é variável em cada doente, pois esta depende de vários fatores e condições do mesmo $(7,28)$. No entanto, a literatura aponta que o processo de CVAH tem a duração de aproximadamente entre uma a três semanas A ingestão de pequenas quantidades de água ou de alimentos é um fator que pode prolongar a morte, sendo da responsabilidade do doente definir a sua ingestão $(17,28)$.

\section{Suicídio Assistido, Eutanásia, Autonomia e Cuidados Paliativos}

Em Portugal, do ponto de vista legal, não existe enquadramento da CVAH. No entanto, existe enquadramento legal sobre a recusa de nutrição e hidratação artificiais. Neste âmbito, se o doente competente pode recusar nutrição e hidratação artificiais, também poderá recusar alimentação e hidratação por via oral mesmo que isso signifique a antecipação da morte. No entanto, do ponto de vista das orientações da The European Association for Parenteral and Enteral Nutrition (ESPEN) a CVAH é uma decisão ética e legalmente aceitável (24).

Alguns autores defendem que a CVAH é considerada uma forma de suicídio (5), porque acelerar a morte é algo feito com certeza e intencionalidade, assegurando que a mesma se cumpre e que o suicídio é a sua causa primária. Consequentemente, tudo isto resulta em que a CVAH seja considerada por alguns autores como moralmente errada (30).

O suicídio assistido é definido como um ato médico em que este fornece, a pedido do doente competente, uma prescrição de um fármaco ou combinação de fármacos letais que o mesmo se autoadministra por ingestão com a intenção explicita e voluntária de terminar com a vida $(14,30)$. Para uma grande parte dos doentes este método não se encontra disponível por ser considerado ilegal (3, 18), sendo por esse motivo que muitos doentes optam pela CVAH, já que esta é uma forma completamente voluntária de antecipar a morte evitando assim não só sofrimento que o doente julga ser intolerável como também a intervenção de terceiros(18). Apesar de em alguns países o suicídio assistido ser legal, alguns autores referem que existem doentes que mesmo assim optam pela $\mathrm{CVAH}(3,7,18)$. As características da relação entre a CVAH com a morte - intenção, certeza e causa - podem considerá-la uma forma de suicídio (30). Ou seja, sendo a CVAH descrita como a recusa voluntária de alimentação e hidratação com o objetivo de antecipar a morte, esta é distinta da perda involuntária de apetite como consequência de uma doença terminal. Deste modo, alguns autores afirmam que a CVAH poderá ser considerada uma forma de suicídio, uma vez que, a intenção de causar a própria morte existe (31). No entanto, na CVAH a decisão do doente é reversível durante os primeiros dias. Assim, podemos diferenciá-la de qualquer forma de suicídio visto que a CVAH ocorre através de um processo de morte mais natural e menos definitivo (17) Outros autores afirmam que a CVAH é um ato em que o doente se mata a si próprio, embora não seja considerado uma ação mas sim uma omissão da ingestão de comida e bebida (17). Contudo, quando uma omissão é intencional esta terá uma causa. Neste sentido, a causa é a morte e assim sendo alguns autores referem que a CVAH poderá ser considerada "suicídio por omissão" (29). A literatura também descreve o suicídio assistido como "ativo" pois exige a ingestão de fármacos letais, enquanto a CVAH é descrita como "passiva", pois cinge-se apenas a parar de comer e beber por livre vontade (6).

Da literatura consultada, é referido que alguns médicos poderão considerar ilegítimo o auxílio ao suicídio ativo e legítimo o auxílio do suicídio passivo. No entanto, de uma forma ou de outra o médico contribui para a antecipação da morte em ambos os casos (32). Por outro lado, a CVAH poderá ser considerada uma alternativa ao suicídio assistido e à eutanásia pois não necessita de envolver outras pessoas na sua execução $(5,16)$, pelo que, é defendido do ponto de vista ético que a CVAH tem a vantagem de não ter uma orientação médica e de manter a privacidade e autonomia do doente (5).

Uma área especialmente conflituante com a CVAH são os cuidados paliativos, pois a CVAH antecipa a morte da pessoa doente, não deixando a doença seguir a sua trajetória natural. Os profissionais de saúde que prestam cuidados paliativos aos doentes que optem pela CVAH não podem ser considerados os agentes da morte desses doentes, a menos que façam algo para acelerar a morte dos mesmos. Nesta perspetiva, os profissionais de saúde não aceleram a morte em maior extensão do que já está a ser acelerada pelos próprios doentes (31). Por outro lado, outros autores afirmam que a CVAH poderá ser considerada diferente do suicídio assistido no qual o médico prescreve medicação letal e, portanto, o ato de causar a morte não é inteiramente da responsabilidade da pessoa doente $(14,19)$.

$\mathrm{Na} \mathrm{CVAH}$, o acompanhamento dos profissionais de saúde consiste em tornar o doente o mais confortável possível ao respeitar a decisão autónoma do mesmo de renunciar à comida e à bebida. Assim, continuar a prestar cuidados paliativos aos doentes que procuram morrer por CVAH e durante essa fase de recusa de comida e bebida não constitui suicídio assistido pese embora não seja possível a prática da CVAH no âmbito da filosofia e dos princípios dos cuidados paliativos, na medida em que a CVAH antecipa a morte e os cuidados paliativos deixam a doença seguir a sua trajetória natural. No entanto, é possível afirmar que o envolvimento dos profissionais de saúde que prestam cuidados paliativos aos doentes que optam por CVAH, não pode ser considerado um incentivo à prática de suicídio assistido, mas sim auxiliar os mesmos para que a CVAH seja confortável através do controlo da dor e dos sintomas emergentes durante este processo (31).

Neste âmbito, a literatura indica que os profissionais de saúde apenas respeitam a decisão autónoma do doente, para que este possa viver o seu fim de vida com as suas escolhas e com o conceito de 
paz e conforto que cada doente tem para si. Esta decisão cabe apenas ao doente sendo o mesmo totalmente responsável pela sua escolha. Desta forma, a CVAH não representa suicídio assistido para os profissionais de saúde (31). No entanto, alguns autores afirmam que existe permissibilidade ética no suicídio assistido pelo médico e, por isso, continua a ser uma questão de disputa ética contínua, reforçando a ideia de que a permissibilidade ética do suicídio e da CVAH estão vinculados, sendo que, a permissibilidade ética do último depende, em parte, da permissibilidade ética do primeiro (12).

A literatura indica que os profissionais de saúde podem apresentar objeção de consciência no âmbito da CVAH, pois alguns profissionais podem considerar esta prática como moralmente censurável ou eticamente errada $(7,31)$. No entanto, mesmo que os profissionais de saúde considerem que é um ato ilegítimo não há qualquer direito de coagir o doente a atuar de outro modo ou mesmo a impor-lhe alimentação e hidratação (16). A CVAH posiciona-se assim entre a liberdade pessoal de todo ser humano para decidir sobre como e quando controlar as circunstâncias da morte e o dever do estado e de cada profissional de saúde de proteger a vida de outro ser humano (17).

De acordo com ESPEN, a renúncia a alimentos e líquidos pode ser considerada uma expressão de morte autodeterminada por meio de uma decisão autónoma em relação à própria vida. Porém, não deve ser confundida com depressão grave ou doença relacionada com falta de apetite, pois os atos suicidas realizam-se na maioria dos casos num contexto psicopatológico em que predomina a depressão (24). Neste âmbito, se o desejo de antecipar a morte por CVAH tiver como base a depressão, optar pela CVAH dificilmente se poderá considerar uma decisão autónoma $(17,24)$.

É necessário ter em atenção que, diversos doentes quando estão perto da morte desenvolvem frequentemente problemas do foro cognitivo, o que pode levar a questionar-se se a CVAH continua a ser voluntária. No caso de existirem sintomas refratários bem como a necessidade de sedar o doente com o seu consentimento, poderá haver um período a partir do qual este dificilmente poderá decidir mudar de ideias quanto a manter-se sem comer e beber. É, assim, de esperar que se instale delirium ligeiro a moderado. Neste caso, poderá acontecer que um doente nestas condições se esqueça da sua decisão e solicite alimentação e/ou hidratação. Esta possibilidade deve estar prevista e deve ser discutida previamente com o doente caso venha hipoteticamente a ocorrer e de forma a não ser coação. Neste caso, se a opção for dar comida e bebida à pessoa doente o processo de morte será atrasado, indo isto contra ao que o doente definiu para si em primeira instância (1, 32, 34-40, 41).

\section{ANÁLISE CRÍTICA}

A CVAH consiste numa decisão de um doente competente que, de forma intencional, opta por morrer sem comer e beber, com o objetivo de antecipar a morte, sendo esta uma ação que só mais recentemente se tem vindo a discutir na literatura.

A literatura refere que a CVAH poderá ser considerada uma alternativa ao suicídio assistido e à eutanásia, para que os doentes possam morrer quando quiserem e em função dos seus próprios critérios. Porém, ainda existem algumas questões éticas em relação a este tema que necessitam ser melhor debatidas. Apesar disso, a CVAH parece ser uma opção de antecipar a morte mais aceitável do que outras formas de terminar com a vida, tais como a eutanásia e o suicídio assistido por não ser necessária a intervenção dos profissionais de saúde (2-39-41). A CVAH aparenta ser a escolha preferencial no que diz respeito à antecipação da morte mais comum do que outras formas de antecipar a morte. Acresce a este facto, a noção de que há ausência de enquadramento legal para esta questão. Assim sendo, não existe um impedimento legal efetivo à sua realização, podendo, no entanto, existir vários graus de aceitação da CVAH em comparação com outras formas de antecipação da morte $(37,41)$.

O Código Deontológico da Ordem dos Nutricionistas engloba os valores e princípios éticos que devem guiar o desempenho dos nutricionistas enquanto profissionais de saúde, valorizando os princípios gerais de autonomia, de não maleficência, de beneficência e de justiça (42). Neste sentido, é também importante discutir a CVAH à luz dos princípios éticos com os quais possa colidir.

Analisando os princípios éticos, a CVAH poderá colidir com os princípios de beneficência, maleficência e autonomia. No que concerne ao princípio de beneficência, este consiste em fazer o bem à pessoa doente, pois moralmente é exigido a cada profissional de saúde que este contribua para o bem da pessoa doente, através de atos e atitudes concretas de ajuda para melhoria da saúde e da qualidade de vida. Ou seja, este princípio não exige apenas que os profissionais de saúde se limitem a agir de forma a evitar prejudicar os doentes mas sim que procurem medidas efetivas para os ajudar (17, 33, 34, 36-38). Já o princípio da não-maleficência traduz-se na obrigação de não causar mal ou dano, proibindo qualquer ação que os possa causar. Este dano caracteriza as situações em que uma determinada ação resulta no prejuízo intencional dos interesses ou dos direitos do doente. No âmbito da CVAH, os profissionais de saúde que acompanham a pessoa doente ou que a informam sobre esta possibilidade quando questionados não causam dano intencional à pessoa doente $(17,33,34,36,37)$.

É necessário ter também em consideração que colocar em prática o princípio de beneficência em situações de CVAH é algo bastante desafiante, pois este princípio é constantemente confrontado com o princípio de autonomia devido ao facto de que não é possível agir sem o consentimento de um agente moral livre, neste caso o doente. Deste modo, determinar o que é bom ou mau constitui uma decisão pessoal, pois o que o profissional de saúde pode considerar bom, o doente poderá não considerar. Neste contexto, importa ainda referir que o princípio de beneficência se encontra amplamente associado ao paternalismo. Contudo, alguns autores defendem que a beneficência não pode ser confundida ou equiparada com o paternalismo, pois implica a usurpação por parte dos profissionais de saúde do direito moral que a pessoa doente possui, como ser humano individual que decide o que é melhor para os seus próprios interesses, neste caso, optar pela CVAH. Assim sendo, o doente não poderá ser influenciado a não optar por CVAH apenas porque o profissional de saúde acredita não ser o melhor ou o mais correto do ponto de vista ético e moral (17, 36-38).

Verifica-se também que o princípio do respeito pela autonomia é aquele que mais sobressai nesta discussão, já que de acordo com alguns autores, o doente competente tem o direito de recusar tratamentos mesmo que isso ponha em risco a sua sobrevida. A nutrição e hidratação artificiais, enquanto forma de tratamento, podem legitimamente ser recusadas pela pessoa doente, o que de uma forma geral não é um direito contestado. Comer e beber não são considerados tratamentos mas sim um cuidado humano básico. Contudo, poderá considerar-se que a recusa voluntária de comer e beber é uma extensão desse direito. Poderá também considerar-se uma forma de suicídio e, assim, ser considerado ilegítimo. No entanto, mesmo que se considere ilegítimo que o doente cesse voluntariamente de comer e beber, não há qualquer direito de coagir o mesmo a proceder de outro modo ou mesmo impor-lhe formas alternativas de alimentação e hidratação (41). 
Cabe referir que é de extrema importância que o doente seja avaliado por psicologia e por psiquiatria antes de iniciar a CVAH, de forma a aferi-se se existem eventuais processos de depressão, doença mental inadequadamente tratada, sintomas não controlados, sofrimento existencial e sinais de coação bem como outras alterações do foro cognitivo que coloquem em causa a decisão de CVAH e a autonomia do doente. Para além disso, é necessário excluir outros fatores que levem à opção de CVAH, tais como: motivos sociais, económicos ou de ausência de retaguarda familiar ou institucional, dado que estes motivos poderão ser passíveis de correção ou melhoria culminando na desistência da pessoa doente em prosseguir com a CVAH (41). Deste modo, procura-se que o processo de tomada de decisão da pessoa doente seja verdadeiramente autónomo e não condicionado. No entanto, o doente poderá optar por recusar este tipo de avaliação (33). É importante ter em consideração que os doentes institucionalizados, esta decisão autónoma poderá ser de difícil aceitação, pelo que, poderão existir casos em que não há o suporte da decisão do doente, sobretudo se estiverem envolvidas crenças, fé, religião e aspectos culturais (41). Alguns autores afirmam que estas instituições e os profissionais que ali trabalham, poderão encarar o acompanhamento destes doentes como pondo-os em risco de serem acusados de negligência ou sentirem-se obrigados a comunicar a CVAH como suicídio (41). Neste âmbito é importante que os registos clínicos da equipa multidisciplinar que acompanha o doente se mantenham claros, fundamentados e atualizados. Os registos que algumas instituições têm de cumprir e que têm como finalidade avaliar a qualidade dos serviços sendo passíveis de ser auditados, poderão levantar dúvidas quanto à justificação do estado nutricional e de hidratação dos doentes e da deterioração mental associada (40).

Sempre que o doente mantiver a sua determinação de morrer sem comer e beber, os profissionais de saúde da equipa multidisciplinar têm a obrigação de continuar a acompanhá-lo e a prestar-Ihes cuidados paliativos através do controlo de sintomas emergentes ou de outras questões que ponham em causa a sua qualidade de vida, podendo no entanto existir casos de objeção de consciência $(17,41)$.

\section{CONCLUSÕES}

A CVAH é um fenómeno complexo que poderá ocorrer em situações de doença avançada, progressiva e incurável. Assim sendo, torna-se primordial que o nutricionista acompanhe o doente de forma holística sempre de acordo com a equipa multidisciplinar, com os tratamentos paliativos que o doente se encontre a realizar e respeitando os seus desejos e necessidades em fim de vida.

\section{REFERÊNCIAS BIBLIOGRÁFICAS}

1. Pinho-Reis CV. Os Cuidados Paliativos Domiciliários, a Alimentação e os Familiares-Cuidadores. Rev Kairós Gerontol [Internet]. 2018 Dec 30;21(5):09-30. Available from: http://dx.doi.org/10.23925/2176-901X.2018v21i4p09-30.

2. Gunning KF, Crowther CA. End of life decisions. BMJ [Internet]. 1997 Nov 1;315(7116):1164-1164. Available from: https://www.bmj.com/lookup/doi/10.1136/ bmj.315.7116.1164.

3. Pope TM, Anderson LE. Voluntarily Stopping Eating and Drinking: A Legal Treatment Option at the End of Life. Widener Law School Legal Studies Research [Internet]. 2011; 17(173):363-427. Available from: https://www.ncbi.nlm.nih.gov/pmc/articles/PMC5649075/. 4. Meier EA, Gallegos J V., Montross-Thomas LP, Depp CA, Irwin SA, Jeste DV. Defining a Good Death (Successful Dying): Literature Review and a Call for Research and Public Dialogue. Am J Geriatr Psychiatry [Internet]. 2016;24(4):261-71. Available from: http:// dx.doi.org/10.1016/j.jagp.2016.01.135.

5. Ivanović N, Büche D, Fringer A. Voluntary stopping of eating and drinking at the end of life - a 'systematic search and review' giving insight into an option of hastening death in capacitated adults at the end of life. BMC Palliat Care [Internet]. 2014 Dec 8;13(1):1. Available from: https://bmcpalliatcare.biomedcentral.com/articles/10.1186/1472-684X-13-1. 6. Pope TM. Introduction: Voluntarily Stopping Eating and Drinking. Narrat Inq Bioeth [Internet]. 2016;6(2):75-77. Available from: https://muse.jhu.edu/article/631802.

7. Bolt EE, Hagens M, Willems D, Onwuteaka-Philipsen BD. Primary Care Patients Hastening Death by Voluntarily Stopping Eating and Drinking. Ann Fam Med [Internet]. $2015 \mathrm{Sep}$ 1;13(5):421-8. Available from: http://www.annfammed.org/cgi/doi/10.1370/afm.1814. 8. Feichtner A, Weixler D, Birklbauer A. Freiwilliger Verzicht auf Nahrung und Flüssigkeit um das Sterben zu beschleunigen. Wiener Medizinische Wochenschrift [Internet]. 2018 May 27;168(7-8):168-76. Available from: http://link.springer.com/10.1007/ s10354-018-0629-z.

9. Pope TM, West A. Legal briefing: Voluntarily stopping eating and drinking. J Clin Ethics [Internet]. 2014;25(1):68-80. Available from: https://pubmed.ncbi.nlm.nih. gov/24779321/.

10. Stängle S, Schnepp W, Fringer A. The need to distinguish between different forms of oral nutrition refusal and different forms of voluntary stopping of eating and drinking. Palliat Care Soc Pract [Internet]. 2019 Jul 9;13:117822421987573. Available from: http:// journals.sagepub.com/doi/10.1177/1178224219875738.

11. Somasundaram O, Tejus MA, Raghavan DV. Jainism - Its relevance to psychiatric practice; with special reference to the practice of Sallekhana. Indian J Psychiatry [Internet]. 2016;58(4):471. Available from: http://www.indianjpsychiatry.org/text. asp?2016/58/4/471/196702.

12. Onwuteaka-Philipsen BD, Brinkman-Stoppelenburg A, Penning C, de Jong-Krul GJ, van Delden JJ, van der Heide A. Trends in end-of-life practices before and after the enactment of the euthanasia law in the Netherlands from 1990 to 2010: a repeated cross-sectional survey. Lancet [Internet]. 2012 Sep;380(9845):908-15. Available from: https://linkinghub.elsevier.com/retrieve/pii/S0140673612610344.

13. Rodríguez-Prat A, Monforte-Royo C, Balaguer A. Ethical Challenges for an Understanding of Suffering: Voluntary Stopping of Eating and Drinking and the Wish to Hasten Death in Advanced Patients. Front Pharmacol [Internet]. 2018 Mar 29;9(MAR):1-5. Available from: http://journal.frontiersin.org/article/10.3389/fphar.2018.00294/full.

14. Schwarz J. Exploring the Option of Voluntarily Stopping Eating and Drinking within the Context of a Suffering Patient's Request for a Hastened Death. J Palliat Med [Internet]. 2007 Dec;10(6):1288-97. Available from: http://www.liebertpub.com/doi/10.1089/ jpm.2007.0027.

15. Jox RJ, Black I, Borasio GD, Anneser J. Voluntary stopping of eating and drinking: is medical support ethically justified? BMC Med [Internet]. 2017 Dec 20;15(1):186. Available from: http://bmcmedicine.biomedcentral.com/articles/10.1186/s12916-017-0950-1.

16. Pinho-Reis C, Sarmento A, Capelas ML. Nutrition and Hydration in the End-of-Life Care: Ethical Issues. Acta Port Nutr. 2018 Dec 31;15:36-40. Available from: http://dx.doi. org/10.21011/apn.2018.1507.

17. Saladin N, Schnepp W, Fringer A. Voluntary stopping of eating and drinking (VSED) as an unknown challenge in a long-term care institution: an embedded single case study. BMC Nurs [Internet]. 2018 Dec 1;17(1):39. Available from: https://bmcnurs.biomedcentral.com/articles/10.1186/s12912-018-0309-8.

18. Gruenewald DA. Voluntarily Stopping Eating and Drinking: A Practical Approach for Long-Term Care Facilities. J Palliat Med [Internet]. 2018 Sep;21(9):1214-20. Available from: https://www.liebertpub.com/doi/10.1089/jpm.2018.0100.

19. Jansen LA. Voluntary Stopping of Eating and Drinking (VSED), Physician-Assisted Suicide (PAS), or Neither in the Last Stage of Life? PAS: No; VSED: It Depends. Ann Fam Med [Internet]. 2015 Sep 1;13(5):410-1. Available from: http://www.annfammed. org/cgi/doi/10.1370/afm.1849.

20. Hudson PL, Kristjanson LJ, Ashby M, Kelly B, Schofield P, Hudson R, et al. Desire for hastened death in patients with advanced disease and the evidence base of clinical guidelines: a systematic review. Palliat Med [Internet]. 2006 Oct 1;20(7):693-701. Available from: http://journals.sagepub.com/doi/10.1177/0269216306071799.

21. Mystakidou K, Rosenfeld B, Parpa E, Katsouda E, Tsilika E, Galanos A, et al. Desire for death near the end of life: the role of depression, anxiety and pain. Gen Hosp Psychiatry [Internet]. 2005 Jul;27(4):258-62. Available from: https://linkinghub.elsevier.com/ retrieve/pii/S0163834305000320. 
22. Breitbart W. Depression, Hopelessness, and Desire for Hastened Death in Terminally III Patients With Cancer. JAMA [Internet]. 2000 Dec 13;284(22):2907. Available from: http:// jama.jamanetwork.com/article.aspx?doi=10.1001/jama.284.22.2907.

23. Balaguer A, Monforte-Royo C, Porta-Sales J, Alonso-Babarro A, Altisent R, Aradilla-Herrero A, et al. An International Consensus Definition of the Wish to Hasten Death and Its Related Factors. Bayer A, editor. PLoS One [Internet]. 2016 Jan 4;11(1):e0146184. Available from: https://dx.plos.org/10.1371/journal.pone.0146184.

24. Druml C, Ballmer PE, Druml W, Oehmichen F, Shenkin A, Singer P, et al. ESPEN guideline on ethical aspects of artificial nutrition and hydration. Clin Nutr [Internet]. 2016;35(3):545-56. Available from: http://dx.doi.org/10.1016/j.clnu.2016.02.006.

25. Rosenfeld B, Pessin H, Marziliano A, Jacobson C, Sorger B, Abbey J, et al. Does desire for hastened death change in terminally ill cancer patients? Soc Sci Med [Internet]. 2014;111:35-40. Available from: http://dx.doi.org/10.1016/j.socscimed.2014.03.027. 26. Schwarz JK. Stopping eating and drinking. Am J Nurs [Internet]. 2009;109(9):53-61. Available from: doi: 10.1097/01.NAJ.0000360314.69620.43.

27. Pope TM. Voluntarily Stopping Eating and Drinking Is Legal and Ethical for Terminally III Patients Looking to Hasten Death. ASCO Post [Internet]. 2018;(April). Available from: https://ascopost.com/issues/june-25-2018/voluntarily-stopping-eating-and-drinking-is-legal-and-ethical/.

28. Schneider B, S Müller R, Sperling U. Voluntarily Stopping Eating and Drinking (VSED): A Suicidological Perspective [Internet]. Vol. 34, GeroPsych: The Journal of Gerontopsychology and Geriatric Psychiatry. 2021;34(2):63-72. Available from: https://doi. org/10.1024/1662-9647/a000252.

29. Menzel PT. Voluntarily stopping eating and drinking: A normative comparison with refusing lifesaving treatment and advance directives. J Law, Med Ethics [Internet]. 2017;45(4):634-46. Available from: https://doi.org/10.1177/1073110517750602.

30. Gerson SM, Bingley A, Preston N, Grinyer A. When is hastened death considered suicide? A systematically conducted literature review about palliative care professionals' experiences where assisted dying is legal. BMC Palliat Care [Internet]. 2019 Dec 31;18(1):75. Available from: https://bmcpalliatcare.biomedcentral.com/articles/10.1186/ s12904-019-0451-4.

31. McGee A, Miller FG. Advice and care for patients who die by voluntarily stopping eating and drinking is not assisted suicide. BMC Med [Internet]. 2017 Dec 27;15(1):222. Available from: https://bmcmedicine.biomedcentral.com/articles/10.1186/s12916-0170994-2.

32. Birnbacher D. Doing and Allowing in the Context of Physician-Assisted Suicide. Erkenntnis [Internet]. 2020 Jun 9;85(3):575-88. Available from: http://link.springer. com/10.1007/s10670-020-00244-1.

33. Wax JW, An AW, Kosier N, Quill TE. Voluntary Stopping Eating and Drinking. J Am Geriatr Soc [Internet]. 2018 Mar;66(3):441-5. Available from: https://onlinelibrary.wiley. com/doi/10.1111/jgs. 15200.

34. Quill TE, Ganzini L, Truog RD, Pope TM. Voluntarily Stopping Eating and Drinking Among Patients With Serious Advanced Illness-Clinical, Ethical, and Legal Aspects. JAMA Intern Med [Internet]. 2018 Jan 1;178(1):123. Available from: http://archinte.jamanetwork.com/article.aspx?doi=10.1001/jamainternmed.2017.6307.

35. Kovács MJ. BIOÉTICA NAS QUESTÕES DA VIDA EDA MORTE. 2003;14(2):115-67. 36. de Andrade JS, Almeida MM, Pinho-Reis C. Bioethical Principles and Nutrition in Palliative Care. Acta Port Nutr [Internet]. 2017;9:12-16. Available from: http://dx.doi. org/10.21011/apn.2017.0903.

37. Pinho-Reis C. Beneficência e Não-maleficência em Fim de Vida: O Caso da Nutrição e Hidratação Artificiais. Rev Kairós Gerontol [Internet]. 2019; 22(4):57-76. Available from: https://doi.org/10.23925/2176-901X.2019v22i4p57-76.

38. Pinho-Reis C. Suporte Nutricional em Cuidados Paliativos. Revista Nutrícias [Internet]. 2012;15:24-27. Available from: http://www.scielo.mec.pt/pdf/nut/n15/n15a06.pdf. 39. Pinho-Reis $C$, Coelho P. Alimentación al final de la vida: un dilema ético. Revista Bioètica \& Debat [Internet]. 2014; 20(72):17-20. Available from: https://www.iborjabioetica.url.edu/sites/default/files/2019-07/72_B_D_es.pdf.

40. Pinho-Reis C, Coelho P. Significado da Alimentação em Cuidados Paliativos. Revista CUIDADOS PALIATIVOS 2014; 1(2):14-22.

41. Gonçalves JASF. A Boa-Morte Ética no Fim de Vida. Lisboa: Coisas de Ler; 2009.
42. Regulamento n. ${ }^{\circ}$ 587/2016. Código Deontológico da Ordem dos Nutricionistas. Diário da República, 2. ${ }^{a}$ Série - N. ${ }^{0} 112$ - 14 de junho de 2016:18664-18666. 